\title{
The clinical implications of recent studies on the structure and function of the retinal microvasculature in diabetes
}

\author{
Carol Yimlui Cheung • M. Kamran Ikram • \\ Ronald Klein • Tien Yin Wong
}

Received: 10 November 2014 / Accepted: 12 January 2015 /Published online: 11 February 2015

(C) Springer-Verlag Berlin Heidelberg 2015

\begin{abstract}
The retinal blood vessels provide the opportunity to study early structural and functional changes in the microvasculature prior to clinically significant microvascular and macrovascular complications of diabetes. Advances in digital retinal photography and computerised assessment of the retinal vasculature have provided more objective and precise measurements of retinal vascular changes. Clinic- and population-based studies have reported that these quantitatively measured retinal vascular changes (e.g. retinal arteriolar narrowing and venular widening) are associated with preclinical structural changes in other microvascular systems (e.g. infarct in the cerebral microcirculation), as well as diabetes and diabetic complications, suggesting that they are markers of early microvascular dysfunction. In addition, there are new retinal imaging techniques to further assess alterations in retinal vascular function (e.g. flicker-induced vasodilatory response, blood flow and oxygen saturation) in diabetes and complications that result from the effects of chronic hyperglycaemia, inflammation and endothelial dysfunction.
\end{abstract}

\footnotetext{
C. Y. Cheung $\cdot$ M. K. Ikram $•$ T. Y. Wong $(\bowtie)$

Singapore Eye Research Institute, Singapore National Eye Centre,

Singapore, 11 Third Hospital Avenue, Singapore 168751,

Republic of Singapore

e-mail: wong.tien.yin@snec.com.sg

C. Y. Cheung $\cdot$ M. K. Ikram $\cdot$ T. Y. Wong

Ophthalmology and Visual Sciences Academic Clinical Programme, Duke-NUS Graduate Medical School, Singapore,

Republic of Singapore

C. Y. Cheung $\cdot$ M. K. Ikram • T. Y. Wong

Department of Ophthalmology, Yong Loo Lin School of Medicine,

National University of Singapore, Singapore, Republic of Singapore

R. Klein

Ocular Epidemiology Research Group, Department of

Ophthalmology and Visual Sciences, The University of Wisconsin,

Madison, WI, USA
}

In this review, we summarise the latest findings on the relationships between quantitatively measured structural and functional retinal vascular changes with diabetes and diabetic complications. We also discuss clinical implications and future research to evaluate whether detection of retinal vascular changes has additional value beyond that achieved with methods currently used to stratify the risk of diabetes and its complications.

Keywords Diabetes - Diabetic complications - Retina . Retinal microvasculature - Retinal vascular changes . Retinal vascular function - Retinal vascular structure . Retinal vessels · Review
Abbreviations
AVR Arteriovenous ratio
CRAE Central retinal artery equivalent
CRVE Central retinal vein equivalent
CVD Cardiovascular disease
DCPD1987 Danish Cohort of Pediatric Diabetes 1987
DMO Diabetic macular oedema
VEGF Vascular endothelial growth factor
WESDR Wisconsin Epidemiologic Study of Diabetic Retinopathy

\section{Introduction}

The number of people with diabetes mellitus is projected to approach 600 million worldwide by 2035 [1]. Microvascular and macrovascular complications are the major causes of morbidity and mortality in diabetic populations [2-4]. While intensive glucose control in patients with diabetes has been found to reduce the risk of microvascular complications, such as diabetic retinopathy [5], the beneficial effects of intensive 
glucose control on macrovascular and cardiovascular endpoints in type 2 diabetes are less clear [6, 7]. Thus, there remains a need to improve early detection of diabetes-related complications, preferably at the preclinical stage, to stratify patients at high and low risk of complications, and to better understand the underlying pathophysiology of these complications.

The retina is both a site of diabetic damage and a 'window' to study early diabetic microvascular complications. Diabetic retinopathy, for example, is one of the earliest clinically observable complications of diabetes, and advanced stage diabetic retinopathy is a major cause of blindness in working adult persons [8]. Also, retinal blood vessels, measuring $100-300 \mu \mathrm{m}$ in size, can easily be assessed for the detection of early changes in the microvasculature. Advances in retinal photography and computer software technologies permit a more objective and precise measurement of retinal vascular changes, such as arteriolar and venular calibres, retinal fractal dimensions and vessel tortuosity [9]. There are also techniques to detect and quantify retinal microaneurysms, and microaneurysm turnover (appearance and disappearance of these lesions over time), a measure of the dynamic process and disease activity in early diabetic retinopathy $[10,11]$. Moreover, new retinal imaging techniques can now assess functional alterations in the retinal vasculature, providing a better understanding of the effects of chronic hyperglycaemia, inflammation and endothelial dysfunction on the microvasculature in diabetes.

In this review, we summarise recent insights into the relationships of quantitatively measured structural and functional retinal vascular changes with diabetes and its complications. We also discuss future research directions and clinical implications.

\section{Effect of hyperglycaemia on the microcirculation}

Hyperglycaemia defines diabetes mellitus and is the cause of microvascular and macrovascular complications [12]. The earliest pathological responses to hyperglycaemia manifest in vascular cells, including endothelial cells, that are exposed to elevated blood glucose levels. In particular, the microvasculature, which has a specific role in regulating blood pressure and offering nutrient delivery, is sensitive to hyperglycaemiainduced damage. The microvasculature also exhibits vasomotion (spontaneous oscillation of small vessels observed in many microvascular beds), permeability and myogenic responses that can adapt flow to local metabolic needs $[13,14]$. The most frequent structural histopathological feature is a thickening of the capillary basement membrane in the glomeruli, retina, skin and other organs. There is a linear relationship between glycosylated haemoglobin levels and the development of microvascular complications [15] such that the criteria (e.g. fasting blood sugar levels) used to define the presence of diabetes are largely derived from the occurrence of microvascular complications, especially retinopathy lesions at or above these levels.

Hyperglycaemia-induced molecular changes are especially evident in capillary endothelial cells in the retina, mesangial cells in the renal glomerulus, and neurons and Schwann cells in peripheral nerves [16]. Other specific cell types may also be involved in microvascular disease in certain tissue beds. In the retina, hyperglycaemia and associated responses such as inflammation, glycation and oxidative stress have been shown to induce the death of contractile cells known as pericytes [17, 18]. Similarly, in the kidney, podocyte injury and loss are a hallmark of diabetic nephropathy [19]. Many mechanisms implicated in microvascular injury are common to endothelial cells, pericytes and podocytes. Endothelial cells in the retinal microvasculature that have been exposed to advanced glycation end-products show abnormal nitric oxide synthase expression and induction of vascular endothelial growth factor (VEGF) expression [20]. Another mechanism that has been implicated in microvascular disease is oxidative stress. Hyperglycaemia promotes the formation of reactive oxygen species, which can cause damage by interacting with macromolecules such as DNA and proteins [20]. In addition to these hyperglycaemia-related pathways, other mechanisms such as dyslipidaemia and inflammation enhance the development of microvascular disease [12]. Although the precise contribution of each of these mechanisms to the development of microvascular complications in diabetes remain unclear, it has been firmly established that improved glycaemic control significantly reduces their occurrence.

\section{Assessment of structural changes in the retinal microvasculature}

The retinal vasculature, consisting essentially of arterioles and venules (rather than arteries or veins), allows direct noninvasive visualisation of the body's microvasculature. Changes in the retinal vasculature can broadly be divided into three groups: (1) classical retinopathy signs, such as diabetic retinopathy, (2) changes in retinal vascular calibre and (3) changes in global geometrical patterns of the retina [9]. These retinal vascular changes in diabetes reflect underlying structural and/or functional alterations resulting from the effects of chronic hyperglycaemia, inflammation, endothelial dysfunction and other pathophysiological mechanisms [21, 22].

Classical retinopathy signs Classical retinal vascular signs are usually seen in patients with systemic diseases such as diabetes (referred to as diabetic retinopathy) or blood pressure (referred to as hypertensive retinopathy). Diabetic retinopathy, a common microvascular complication, is broadly divided into: 
(1) an early stage of non-proliferative retinopathy characterised by a spectrum of retinal vascular signs such as microaneurysms, haemorrhages, cotton wool spots and hard exudates; and (2) a later stage of proliferative disease, which is characterised by neovascularisation [8]. Retinopathy signs are relatively late indicators of target organ damage in the eye and reflect advanced stages of structural microvascular damage, including breakdown of the blood-retinal barrier. Standard ophthalmoscopic examinations and fundus photography are currently used clinically to follow changes in the presence and severity of these retinal signs.

Retinal vascular calibre Changes in the calibre of the retinal vessel, especially widening of the venules, has long been thought to indicate progression of diabetic retinopathy, with increased risk of developing functional abnormalities in the kidney and the eye. Over the last two decades, several computer software systems have been specially designed to measure retinal vascular calibre (or retinal vessel diameter) to document generalised retinal vessel narrowing or widening more objectively and reliably (Fig. 1). Retinal vascular calibre is measured in terms of central retinal artery equivalent (CRAE), central retinal vein equivalent (CRVE) and arteriovenous ratio (AVR) $[23,24]$. CRAE is a summary index reflecting the average width of retinal arterioles, and CRVE is a summary index reflecting the average width of retinal venules. CRAE and CRVE reflect distinct systemic vascular physiology and disease pathways that tend to target the arterial and venous systems specifically. AVR is a dimensionless ratio of arteriole to venous calibre and has been used to control for magnification differences from camera lenses and refractive error. However, AVR is non-specific, and changes in AVR may reflect changes in arterioles or venules, or both. It should be noted that computer-assisted measurement of retinal vascular calibre from retinal photographs only measures the width of the reflective erythrocyte column and underestimates the true internal vessel calibre, as it does not measure the surrounding clear plasma zone. Figure 2 shows examples of narrowed retinal arterioles and widened retinal venules.

Global geometrical patterns in retinal vasculature The human circulatory system is a branching system that conforms to optimum design principals (i.e. Murray's principle) [25]. The optimal retinal vascular architecture will deliver the most efficient blood flow, and deviations or alterations from optimal retinal vascular architecture are thought to result in impaired microcirculatory transport, increased shear stress, reduced efficiency and, hence, a greater risk of vascular damage. Diabetes is known to be associated with increased shear stress and microvacular endothelial dysfunction [26]. In addition to retinopathy signs and retinal vascular calibre, a range of new retinal vascular measures are being explored to quantify the geometric branching network (e.g. fractal dimension, tortuosity, branching, length:diameter ratio, optimality ratio, deviation of junction exponent) of the retinal vasculature in different systemic diseases. These newer retinal vascular measures may reflect the 'optimal state' of blood distribution in the microvasculature. Several systems have been developed to measure these geometric patterns [27-31]. Figure 3 shows the Singapore I Vessel Assessment software (SIVA, National University of Singapore, Singapore) quantitatively measuring retinal vascular structure from a retinal fundus photograph [31, 32].

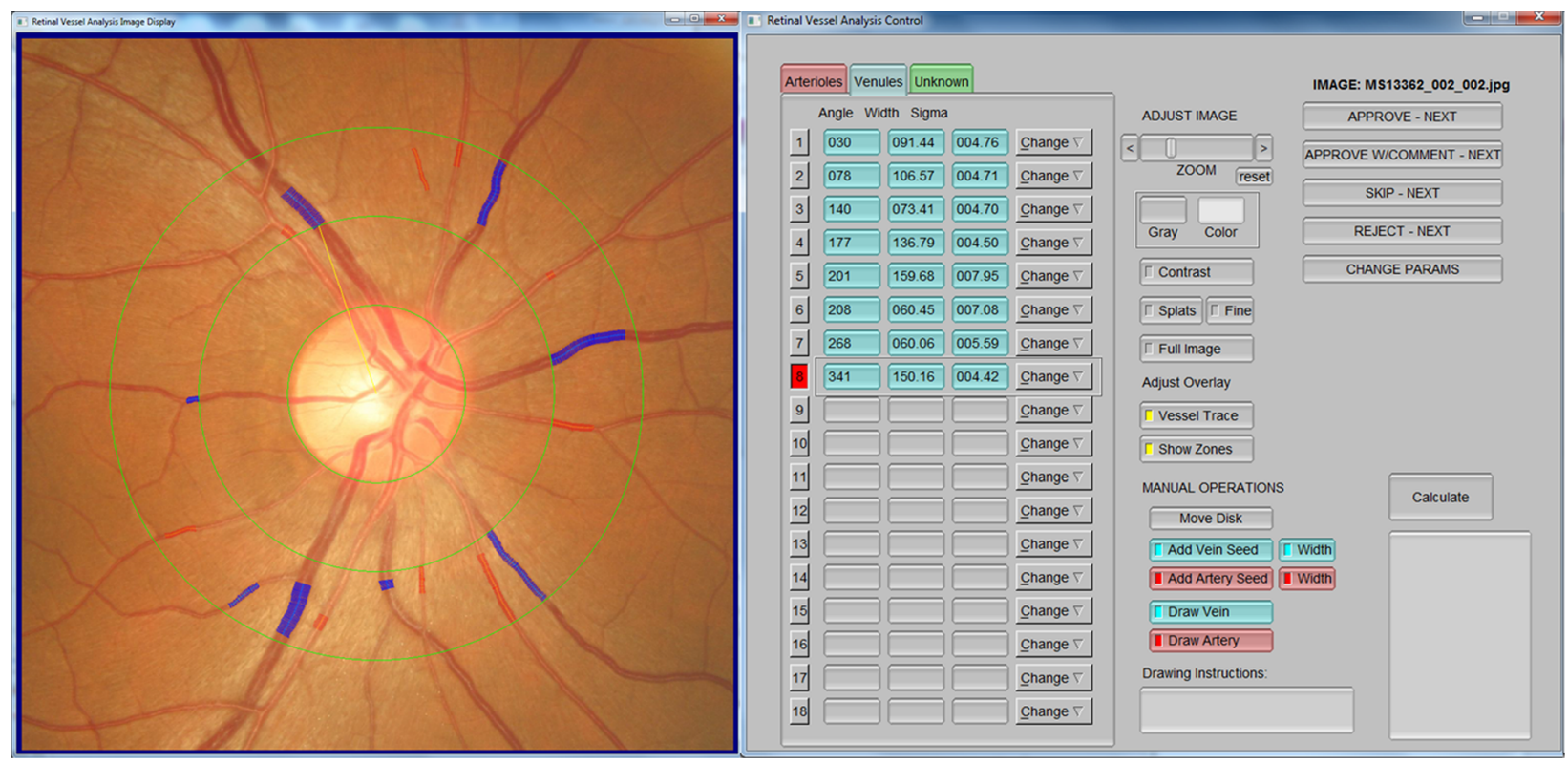

Fig. 1 Measurement of CRAE, CRVE and AVR using the Interactive Vessel Analysis software (IVAN). Arterioles are in red and venules are in blue 

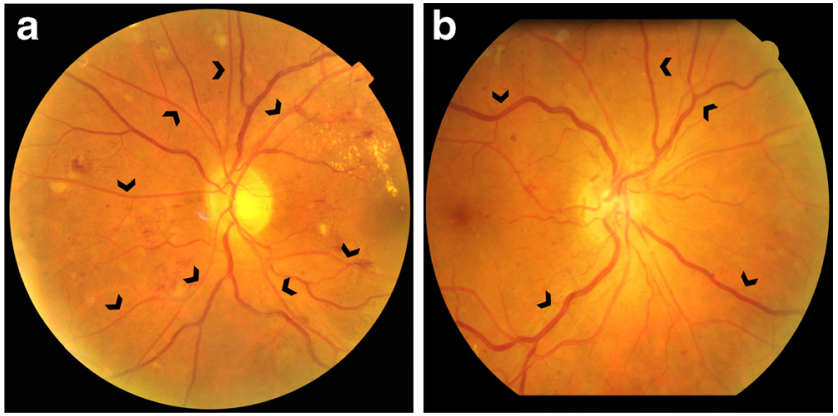

Fig. 2 Examples of (a) narrowed retinal arterioles and (b) widened retinal venules (indicated by arrows)
Microaneurysm count and turnover Markers of progression of diabetic retinopathy include not only the presence of microaneurysm, the earliest clinically recognisable feature of diabetic retinopathy, but also rates of microaneurysm formation and disappearance (turnover) and microaneurysm count change over time [33, 34]. Microaneurysms appear and disappear in the retina of diabetic patients over time, disappearing by closing down due to thrombosis, while new ones appear in different locations of the vascular tree [11]. The RetmarkerDR software (Critical Health SA, Coimbra, Portugal) was recently developed to analyse microaneurysm turnover (microaneurysm formation and disappearance per time interval) in colour fundus photographs [11]. Recent studies showed

\section{a}

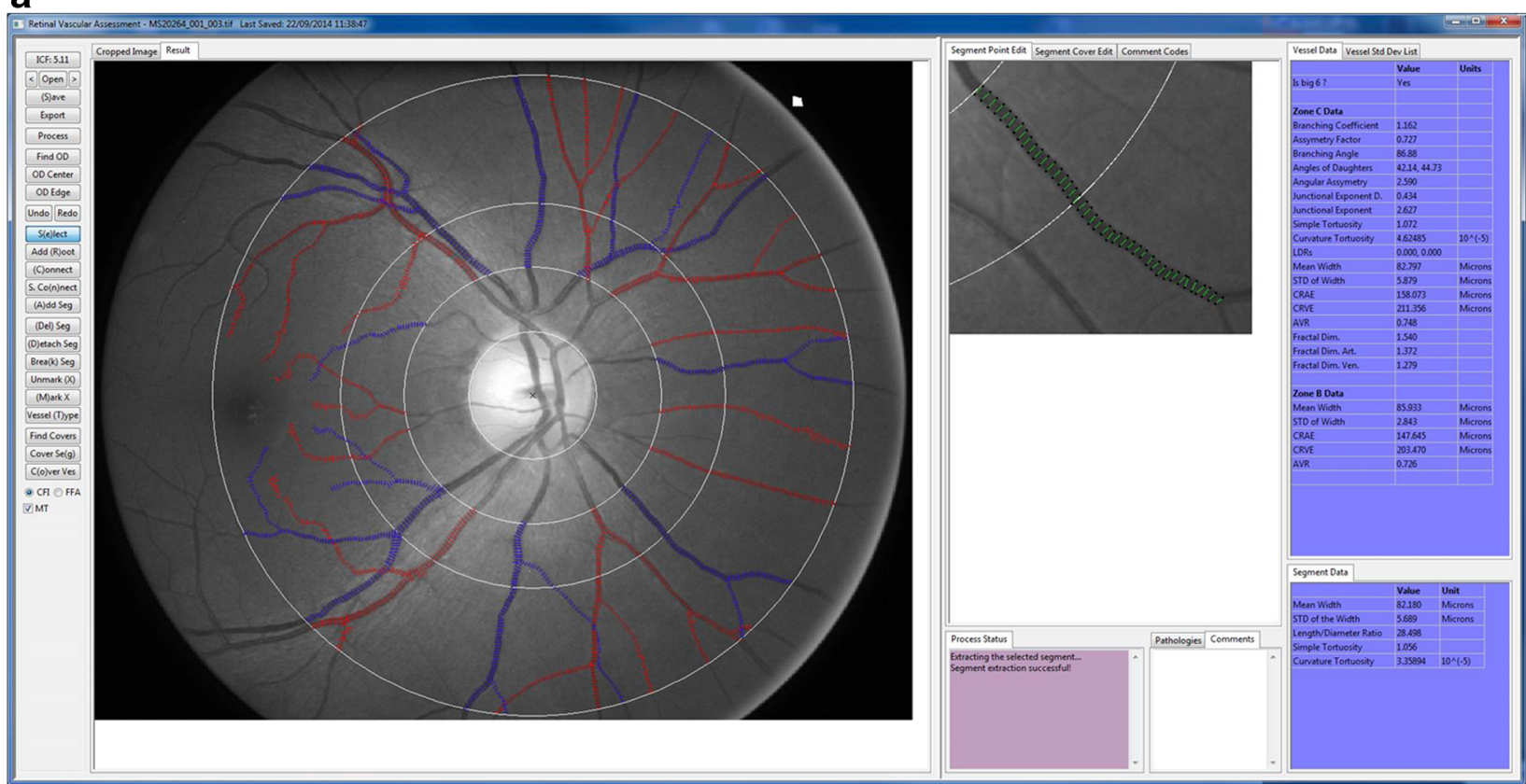

b

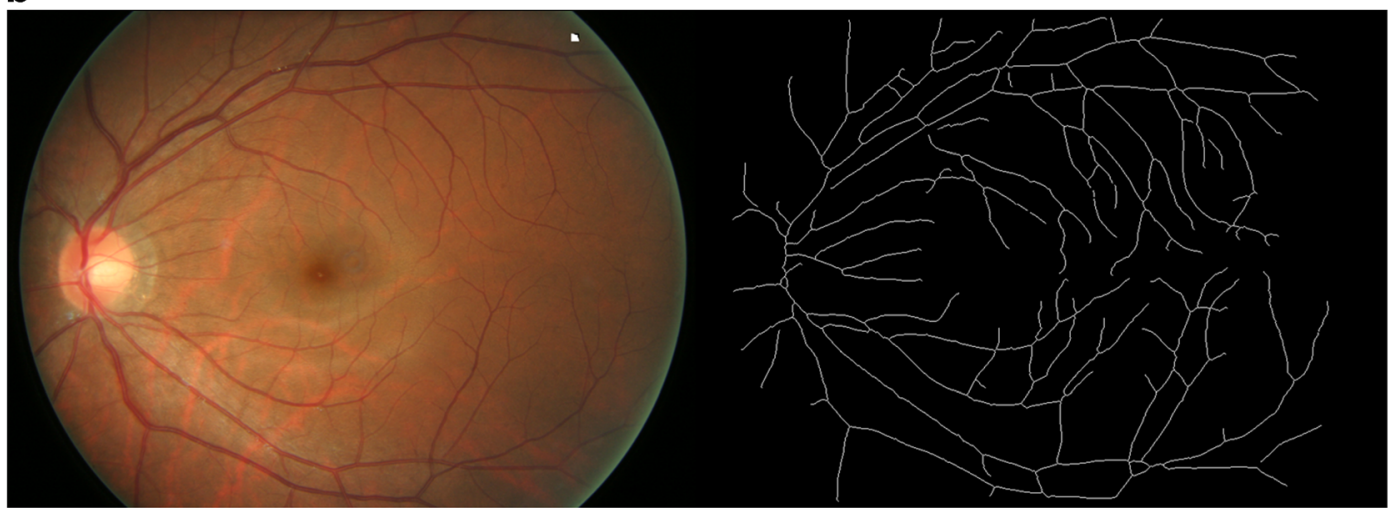

Fig. 3 (a) Measurement of retinal vascular structure using the Singapore I Vessel Assessment software (SIVA). (b) Fractal dimension is a measure of a fractal structure, which exhibits the property of self-similarity, characterising the distribution of a branching vascular system in twodimensional space. In SIVA, fractal dimension is calculated from a skeletonised line tracing using the box-counting method, in which each digital photograph is divided into a series of squares for various side lengths and then the number of boxes is counted. Higher values, reflecting increased complexity, are represented by a higher density of the spacefilling pattern of the retinal vascular tree 
that a high turnover, based on the results of computer-assisted detection, is a predictor for the development of diabetic macular oedema (DMO) in eyes with non-proliferative diabetic retinopathy $[10,11,35]$ and for anti-VEGF treatment response in eyes with macular oedema [36]. These studies suggest that microaneurysm turnover can identify diabetic patients at higher risk for worsening of retinopathy and may be an indicator of vascular disease activity.

\section{Retinal vascular changes associated with diabetes}

A number of epidemiological studies have shown that retinal vascular changes, particularly changes in retinal vascular calibre, reflect early microvascular processes in diabetes and in people at risk of diabetes. Table 1 summarises the associations between quantitative retinal vascular measures with diabetes in population-based prospective and cross-sectional studies.

As microvascular alterations may result in a reduced ability of insulin to mediate glucose uptake in skeletal muscles, microvascular disease has been hypothesised to contribute to the development of diabetes [26, 37]. Retinal arteriolar narrowing has been reported to be associated with increased risk of diabetes in middle-aged people without diabetes in the Atherosclerosis Risk in Communities study [37]. This observation was subsequently replicated in the Beaver Dam Eye Study, which had a longer follow-up period of more than 10 years [38], and in the Australian Diabetes, Obesity and Lifestyle study, which used a more precise definition for diagnosing diabetes (OGTT) [42]. The prospective data provided by these studies indicate that narrowed retinal arterioles precede the development of diabetes and thus suggest that arteriolar changes may play a role in the early phases of disease development. In contrast, data from the Rotterdam Study indicated that retinal venular widening, rather than arteriolar narrowing, was associated with incident diabetes and impaired fasting glucose [39]. Thus, it is still unclear whether retinal vascular changes in non-diabetic individuals are markers of future diabetes risk.

In population-based cross-sectional studies, retinal arteriolar widening, rather than arteriolar narrowing, was associated with

Table 1 Relationship of retinal vascular changes with diabetes in population-based studies

\begin{tabular}{|c|c|c|c|c|}
\hline Study and year & Study type and sample size & $\begin{array}{l}\text { Measure of retinal } \\
\text { vascular changes }\end{array}$ & Outcomes & Summary of findings \\
\hline $\begin{array}{l}\text { The Atherosclerosis Risk in } \\
\text { Communities Study } \\
\text { (2002) [37] }\end{array}$ & $\begin{array}{l}\text { Population-based prospective } \\
\quad \text { study }(n=7,993)\end{array}$ & AVR & $\begin{array}{l}\text { Incident type } 1 \\
\quad \text { diabetes }(n=291)\end{array}$ & $\begin{array}{l}\text { Lower AVR associated with } \\
\text { incident diabetes }\end{array}$ \\
\hline $\begin{array}{l}\text { The Beaver Dam Eye } \\
\text { Study (2005) [38] }\end{array}$ & $\begin{array}{l}\text { Population-based prospective } \\
\quad \text { study }(n=3,251)\end{array}$ & AVR & $\begin{array}{l}\text { Incident type } 2 \\
\quad \text { diabetes }(n=249)\end{array}$ & $\begin{array}{l}\text { Lower AVR associated with } \\
\text { incident diabetes }\end{array}$ \\
\hline $\begin{array}{l}\text { The Rotterdam study } \\
\text { (2006) [39] }\end{array}$ & $\begin{array}{l}\text { Prospective population-based } \\
\quad \text { study }(n=2,309)\end{array}$ & CRAE, CRVE & $\begin{array}{l}\text { IFG }(n=305) \\
\text { Diabetes }(n=118)\end{array}$ & $\begin{array}{l}\text { Wider venular calibre associated } \\
\text { with incident IFG and diabetes }\end{array}$ \\
\hline $\begin{array}{l}\text { The Blue Mountains Eye } \\
\text { Study (2007) [40] }\end{array}$ & $\begin{array}{l}\text { Population-based cross-sectional } \\
\text { study }(n=3,654)\end{array}$ & CRAE, CRVE & $\begin{array}{l}\text { IFG }(n=121) \\
\text { Diabetes }(n=255)\end{array}$ & $\begin{array}{l}\text { Wider arteriolar calibre associated } \\
\text { with diabetes }\end{array}$ \\
\hline $\begin{array}{l}\text { The Australian Diabetes, } \\
\text { Obesity and Lifestyle } \\
\text { study (2007) [41] }\end{array}$ & $\begin{array}{l}\text { Population-based cross-sectional } \\
\text { study }(n=1,998)\end{array}$ & CRAE, CRVE & $\begin{array}{l}\text { IGT/IFG }(n=960) \\
\text { Diabetes }(n=657)\end{array}$ & $\begin{array}{l}\text { Wider arteriolar calibre associated } \\
\text { with IGT/IFG and diabetes }\end{array}$ \\
\hline $\begin{array}{l}\text { The Australian Diabetes, } \\
\text { Obesity and Lifestyle } \\
\text { Study (2008) [42] }\end{array}$ & $\begin{array}{l}\text { Population-based prospective } \\
\text { study }(n=803)\end{array}$ & CRAE, CRVE & $\begin{array}{l}\text { Incident diabetes } \\
\quad(n=108)\end{array}$ & $\begin{array}{l}\text { Narrower arteriolar calibre } \\
\text { associated with incident } \\
\text { diabetes }\end{array}$ \\
\hline $\begin{array}{l}\text { The Multi-Ethnic Study } \\
\text { of Atherosclerosis } \\
\text { (2009) [43] }\end{array}$ & $\begin{array}{l}\text { Population-based cross-sectional } \\
\text { study }(n=4,585)\end{array}$ & CRAE, CRVE & $\begin{array}{l}\text { IFG }(n=499) \\
\text { Diabetes }(n=892)\end{array}$ & $\begin{array}{l}\text { Wider arteriolar and venular } \\
\text { calibres associated with } \\
\text { diabetes. Wider venular calibre } \\
\text { associated with increasing } \\
\text { levels of fasting glucose and } \\
\mathrm{HbA}_{1 \mathrm{c}} \text { levels }\end{array}$ \\
\hline $\begin{array}{l}\text { Singapore Malay Eye } \\
\text { Study (2009) [44] }\end{array}$ & $\begin{array}{l}\text { Population-based cross-sectional } \\
\text { study }(n=3,004)\end{array}$ & CRAE, CRVE & Diabetes $(n=682)$ & $\begin{array}{l}\text { Wider retinal arteriolar calibre } \\
\text { associated with diabetes }\end{array}$ \\
\hline $\begin{array}{l}\text { The Singapore Indian } \\
\text { Study (2011) [45] }\end{array}$ & $\begin{array}{l}\text { Population-based cross-sectional } \\
\text { study }(n=3,043)\end{array}$ & CRAE, CRVE & $\begin{array}{l}\text { Prevalent diabetes } \\
\quad(n=980)\end{array}$ & $\begin{array}{l}\text { Wider retinal arteriolar calibre } \\
\text { associated with diabetes }\end{array}$ \\
\hline $\begin{array}{l}\text { Singapore Malay Eye } \\
\text { Study (2012) [46] }\end{array}$ & $\begin{array}{l}\text { Population-based cross-sectional } \\
\quad \text { study }(n=2,141)\end{array}$ & $\begin{array}{l}\text { Tortuosity, branching } \\
\text { angle, fractal } \\
\text { dimension, CRAE, } \\
\text { CRVE }\end{array}$ & $\begin{array}{l}\text { Prevalent diabetes } \\
\qquad(n=594)\end{array}$ & $\begin{array}{l}\text { Lower arteriolar tortuosity, wider } \\
\text { arteriolar and wider venular } \\
\text { calibre associated with diabetes }\end{array}$ \\
\hline
\end{tabular}

IFG, impaired fasting glucose; IGT, impaired glucose tolerance 
prevalent diabetes, impaired glucose tolerance and impaired fasting glucose [40, 41, 43-45]. It is postulated that in the diabetic retina, hyperglycaemia and hypoxia result in retinal vasodilation, leading to hyperperfusion (early vascular change). Nevertheless, there may be racial/ethnic variations in the association between retinal vascular calibre and diabetes. For example, in the Multi-Ethnic Study of Atherosclerosis, the cross-sectional association between retinal arteriolar widening and diabetes was seen mainly in white individuals, whereas the cross-sectional association between retinal venular widening and diabetes was only observed in non-white individuals (Hispanic and Chinese) [43].

The Singapore Malay Eye Study (SiMES) further explored the associations between a series of other retinal vascular network measures (tortuosity, branching angle and fractal dimension) with prevalent diabetes [46]. People with diabetes had straighter (less tortuous) arterioles than people without diabetes, whereas venular tortuosity, arteriolar and venular branching angle and fractal dimension were not significantly different between two groups. This finding of straighter arterioles amongst diabetic individuals, however, is in contrast with the findings of a clinic-based study, which found that people with diabetes had more tortuous retinal arterioles and venules than people without diabetes [47]. Clearly, prospective data are needed.

Key diabetes-related factors, such as longer duration of diabetes and higher $\mathrm{HbA}_{1 \mathrm{c}}$ levels have been crosssectionally associated with retinal vascular network changes (e.g. larger arteriolar branching angle and increased arteriolar tortuosity) in young type 1 diabetic individuals, even in those without evidence of retinopathy, suggesting that changes in the retinal vascular networks may be early markers of diabetes-related microvascular injury [48].

Hypertension and ageing have profound effects on the retinal vasculature, particularly on retinal arteriolar narrowing, increased wall:lumen ratio and rarefaction of retinal vasculature, in non-diabetic individuals $[9,49]$. These factors should be taken into account when studying the independent associations between retinal vascular changes and diabetes.

\section{Retinal vascular changes associated with diabetic microvascular complications}

Diabetic retinopathy In terms of diabetic microvascular complications, studies have primarily focused on the association between retinal vascular calibre and the risk of diabetic retinopathy. For type 1 diabetes, studies have in general suggested that retinal vascular calibre may be associated with the risk of diabetic retinopathy-related outcomes, though the data are not entirely consistent. In the Wisconsin Epidemiologic Study of Diabetic Retinopathy (WESDR), both wider retinal arteriolar and venular calibres measured at baseline were associated with an increased risk of progression of diabetic retinopathy, but were not associated with the 4 year incidence of diabetic retinopathy [22]. In another study, among 468 African-Americans, neither arteriolar nor venular calibres were related to incident diabetic retinopathy [50]. In contrast, wider arteriolar calibre, but not venular calibre, at baseline was associated with an increased risk of diabetic retinopathy in a study that included 645 Australian children and adolescents with type 1 diabetes [51]. Recently, wider venular calibre, narrower arteriolar calibre and lower fractal dimension measured at baseline were shown to be associated with the 16 year incidence of proliferative diabetic retinopathy in a population-based young Danish cohort with type 1 diabetes $[52,53]$. For type 2 diabetes, neither arteriolar nor venular calibres has been found to be associated with the incidence or progression of diabetic retinopathy $[54,55]$. This discrepancy between the findings in patients with type 1 and 2 diabetes may be due to differences across these studies in the distribution of age, confounding effect of other cardiovascular risk factors such as presence of hypertension ( $20 \%$ among patients with type 1 diabetes vs $\sim 70 \%$ in type 2 diabetes), sample sizes and follow-up periods [56].

Two studies have examined whether longitudinal changes in calibres are related to the risk of diabetic retinopathy. In both type 1 and 2 diabetes, widening of the venules was independently associated with a subsequent increased incidence of diabetic retinopathy and increased risk of diabetic retinopathy progression $[55,57]$. Thus, retinal venular dilation appears to be involved in pathological processes associated with diabetic retinopathy, possibly through mechanisms such as impaired vascular autoregulation and hyperperfusion, tissue hypoxia and ischaemia, and aggravating risk factors such as hypertension.

In addition to vascular abnormalities, the neurosensory retina may be primarily affected in diabetes. Whether diabetic retinopathy is primarily a neurogenic or vascular disease is subject to debate. It has been suggested that the retinal dysfunction associated with diabetes may be viewed as a change in the retinal neurovascular unit, providing new insights into the pathophysiology related to both vascular dysfunction and neural degeneration, and this may be essential for identifying new therapeutic targets $[58,59]$.

Diabetic nephropathy Several studies have examined the associations between retinal vascular calibres and diabetic nephropathy. In a clinical trial of type 1 diabetic individuals both baseline and subsequent changes over time in retinal vascular calibres were independently related to changes in renal structural variables, such as glomerular basement membrane width, mesangial matrix fractional volume and glomerulopathy index, as measured on sequential biopsies [60]. In participants with type 2 diabetes in the WESDR study, retinal venular calibre, but not arteriolar calibre, was independently 
associated with the 10 year incidence of a combined outcome, defined as development of gross proteinuria, initiation of renal dialysis or renal transplantation during follow-up [54]. In the same study, these associations were also confirmed among patients with type 1 diabetes [61]. In the Danish Cohort of Pediatric Diabetes 1987 (DCPD1987) with type 1 diabetes, wider venular calibre, narrower arteriolar calibre and lower fractal dimension measured at baseline were associated with the development of nephropathy at the 16 year follow-up [52, 53].

Diabetic neuropathy Fewer studies have evaluated the relationship between retinal vascular changes and diabetic neuropathy. In a cross-sectional study of multi-ethnic Asians with diabetes, wider arteriolar calibre was independently associated with peripheral neuropathy as diagnosed by neurothesiometer or monofilament sensory testing [62]. Another population-based cross-sectional study reported that suboptimal arteriolar calibre and larger arteriolar branching coefficient, as well as diabetic retinopathy and focal arteriolar narrowing, were associated with peripheral neuropathy [63]. In contrast, a population-based study among type 1 diabetics did not find retinal arteriolar calibre to be associated with neuropathy [64].

At present, the DCPD1987 study is the only study to provide longitudinal data on the relationship between retinal vascular calibre and peripheral neuropathy in type 1 diabetes. The findings of this study indicated that the 16 year incidence of diabetic peripheral neuropathy was associated with narrower arteriolar calibre, wider venular calibre and lower fractal dimension at baseline [52, 53].

\section{Retinal vascular changes associated with diabetic macrovascular complications}

Micro- and macrovascular complications of diabetes share certain pathophysiological mechanisms. First, signs of diabetic retinopathy are independent risk markers for cardiovascular disease (CVD) in diabetes [65-67]. Quantitative retinal vascular measures such as retinal vascular calibre have also been associated with CVD in the general population in several large epidemiological studies $[9,49]$. However, these associations have not been extensively studied in people with diabetes. Table 2 summarises the associations between quantitative retinal vascular measures and macrovascular complications in diabetic cohorts.

In the WESDR study, lower AVR, reflecting retinal arteriolar narrowing, was associated with increased risk of heart disease mortality amongst type 1 diabetic individuals over a 20 year interval [68]. Two other prospective cohort studies of type 1 diabetics have reported similar findings. In the New Jersey 725 study, retinal arteriolar narrowing was associated with the incidence of any CVD and lower extremity arterial disease [50]. In the Pittsburgh Epidemiology of Diabetes Complications Study, retinal arteriolar narrowing was associated with the incidence of coronary artery disease in women, but not in men [69] In another WESDR study report, retinal

Table 2 Relationship of retinal vascular changes with macrovascular complications in diabetic cohorts

\begin{tabular}{|c|c|c|c|c|}
\hline Study and year & Study type and sample size & $\begin{array}{l}\text { Measure of retinal } \\
\text { vascular changes }\end{array}$ & Outcomes & Summary of findings \\
\hline $\begin{array}{l}\text { Wisconsin Epidemiologic } \\
\text { Study of Diabetic } \\
\text { Retinopathy (2004) [68] }\end{array}$ & $\begin{array}{l}\text { Population-based prospective } \\
\text { study of type } 1 \text { diabetes } \\
(n=996)\end{array}$ & CRAE, CRVE, AVR & $\begin{array}{l}\text { Incidences of CVD (angina, } \\
\text { myocardial infarction, } \\
\text { stroke) and mortality }\end{array}$ & $\begin{array}{l}\text { Lower AVR associated with } \\
\text { incident heart disease } \\
\text { mortality }\end{array}$ \\
\hline $\begin{array}{l}\text { Wisconsin Epidemiologic } \\
\text { Study of Diabetic } \\
\text { Retinopathy (2007) [54] }\end{array}$ & $\begin{array}{l}\text { Population-based prospective } \\
\text { study of type } 2 \text { diabetes } \\
(n=1,370)\end{array}$ & CRAE, CRVE, AVR & $\begin{array}{l}\text { Incidence of ischaemic heart } \\
\text { disease and stroke mortality }\end{array}$ & $\begin{array}{l}\text { Wider venular calibre } \\
\text { associated with stroke } \\
\text { mortality }\end{array}$ \\
\hline $\begin{array}{l}\text { Pittsburgh Epidemiology } \\
\text { of Diabetes Complications } \\
\text { Study (2009) [69] }\end{array}$ & $\begin{array}{l}\text { Prospective cohort study } \\
\text { of type } 1 \text { diabetes } \\
(n=448)\end{array}$ & CRAE, CRVE, AVR & $\begin{array}{l}\text { Incidence of coronary artery } \\
\text { disease }\end{array}$ & $\begin{array}{l}\text { Narrower arteriolar calibre } \\
\text { associated with incidence } \\
\text { of coronary artery disease } \\
\text { in women, but not men }\end{array}$ \\
\hline $\begin{array}{l}\text { Danish cohort with type } 1 \\
\text { diabetes (2009) [70] }\end{array}$ & $\begin{array}{l}\text { Cross-sectional study of } \\
\quad \text { type } 1 \text { diabetes }(n=208)\end{array}$ & $\begin{array}{l}\text { Retinal vascular } \\
\text { fractal dimension }\end{array}$ & $\begin{array}{l}\text { Presence of macrovasular } \\
\text { disease (stroke, coronary } \\
\text { heart disease and peripheral } \\
\text { artery disease) }\end{array}$ & $\begin{array}{l}\text { Fractal dimension not associated } \\
\text { with macrovascular disease }\end{array}$ \\
\hline $\begin{array}{l}\text { New Jersey } 725 \\
\quad \text { Study (2012) [50] }\end{array}$ & $\begin{array}{l}\text { Prospective cohort study } \\
\text { of type } 1 \text { diabetes } \\
(n=468)\end{array}$ & CRAE, CRVE & $\begin{array}{l}\text { Incidence of hypertension, any } \\
\text { CVD (heart disease, stroke, } \\
\text { or LEAD), and mortality }\end{array}$ & $\begin{array}{l}\text { Narrower arteriolar calibre } \\
\text { associated with incidence } \\
\text { of any CVD and lower } \\
\text { extremity arterial disease }\end{array}$ \\
\hline
\end{tabular}

LEAD, lower extremity arterial disease 
venular widening was associated with increased risk of stroke mortality in type 2 diabetes [54]. These data consistently support the hypothesis that retinal microvascular abnormalities precede macrovascular events. Nevertheless, the pathways linking the microvascular to macrovascular characteristics require further research.

Although retinal vascular fractal dimension is related to microvascular complications in diabetes (discussed above), Grauslund et al found no significant association between retinal vascular fractal dimension and prevalent CVD in a Danish cohort of type 1 diabetes [70]. These data suggest that retinal fractals may have a closer relationship with microvascular complications than with macrovascular complications.

\section{Assessing functional changes of the retinal microvasculature}

Microvascular changes such as impaired reactivity and disturbed blood flow in microvessels have also been hypothesised to contribute to the pathogenesis of diabetes [26]. In contrast to measurement of retinal vascular changes from a single retinal photograph, new retinal imaging technologies can now evaluate retinal microvascular functions in real time. These include flicker-induced vasodilatory response, retinal blood flow and retinal oxygen saturation.

Flicker-induced vasodilatory response Flickering light stimulates neural retina activity and leads to retinal vessel dilation as a result of the release of vasodilating factors, especially nitric oxide, from endothelial and neural cells. It is hypothesised that the response of retinal vessels to flickering light is a measure of endothelial function of the retinal microcirculation [71]. The flicker-induced response can now be measured non-invasively using the Dynamic Vessel Analyzer (IMEDOS, Jena, Germany) in human eyes (Fig. 4).

Several studies reported that the flicker light-induced vasodilation is reduced in individuals with diabetes [72-76] and those with impaired glucose tolerance [77], and is further impaired with increasing severity of diabetic retinopathy [72, 73]. It has been suggested that endothelial dysfunction may underlie this reduced response in diabetes. Sasongko et al reported that serum apolipoprotein levels may possibly be a better biomarker of diabetic retinopathy compared with traditional lipids, as they were associated with flicker-light retinal arteriolar vasodilation and retinal arteriolar tortuosity in people with diabetes [78]. Impaired flicker light-induced vasodilation has been found to be associated with wider retinal vascular calibre in people with diabetes and in people with or at high risk of coronary artery disease, independent of traditional risk factors $[79,80]$. This information may provide further insights into the pathophysiological relationships and mechanisms underlying the relationship of serum apolipoprotein,
Fig. 4 (a) Assessment of the flicker-induced vasodilatory response in the retina using the Dynamic Vessel Analyzer (DVA). (b) Retinal vascular response to flicker light is represented by an average percentage increase over baseline diameter as calculated by the software over three measurement cycles. Examples of flicker light-induced retinal vasodilation in (c) an individual without and (d) a patient with diabetic retinopathy. The summary data will be reflected as percentage of arterial dilation (thick red line) or percentage of venular dilation (thick blue line). The two green lines demarcate the region of normal dilation of the vessels. Other variables as calculated by the software include diameter of the examined vessel, valid percentage (indicates the total number of examined values in relation to the total time of examination), maximum dilatation and maximum constriction of the vessel, and difference between constriction and dilatation. Flicker light-induced retinal vasodilation is reduced in the patient with diabetic retinopathy compared with that in the individual without diabetic retinopathy

retinal vascular variables and diabetic vascular complications. It is notable that impaired flicker light-induced vasodilation can also reflect neurodegeneration, as retinal blood flow is coupled with neuronal activity. Thus, reduced flicker lightinduced vasodilation may reflect damage to both the retinal neural tissue and microcirculation in diabetes [71].

Retinal blood flow Alterations in blood flow affect the delivery of oxygen and metabolic substrates necessary for the maintenance of retinal structure and function. Retinal blood flow can be estimated non-invasively by a bidirectional laser Doppler velocimetry system, which measures the absolute values of the red blood cells flowing in the centre line of the main retinal vessels. Laser Doppler flowmetry and laser speckle flowgraphy can also be used to quantify retinal blood flow noninvasively to evaluate the retinal haemodynamics [81, 82].

Alterations in retinal blood flow have been found in both diabetic humans and animal models of diabetes [83]. However, the different studies have reported contrasting findings, which may reflect the complex pathological alterations that occur in the diabetic retina [83]. For example, some studies reported that in individuals with early diabetes and early stage diabetic retinopathy, retinal blood flow was decreased, compared with that in non-diabetic controls. This suggests that decreased blood flow may be associated with endothelial dysfunction and that the decreased blood flow may result in a reduction of nutrient delivery to the retinal tissue that may contribute to the resultant development of microvascular changes $[84,85]$. However, Patel et al have found that increased retinal blood flow was associated with early diabetic retinopathy [86]. In a longitudinal study, Konno et al showed an initial decrease in retinal blood flow and then an increase with longer disease duration in prospective diabetic patients [87]. Although alterations in retinal blood flow may appear before any clinical symptoms, none of the above techniques has found its way into clinical practice. 


\section{a}

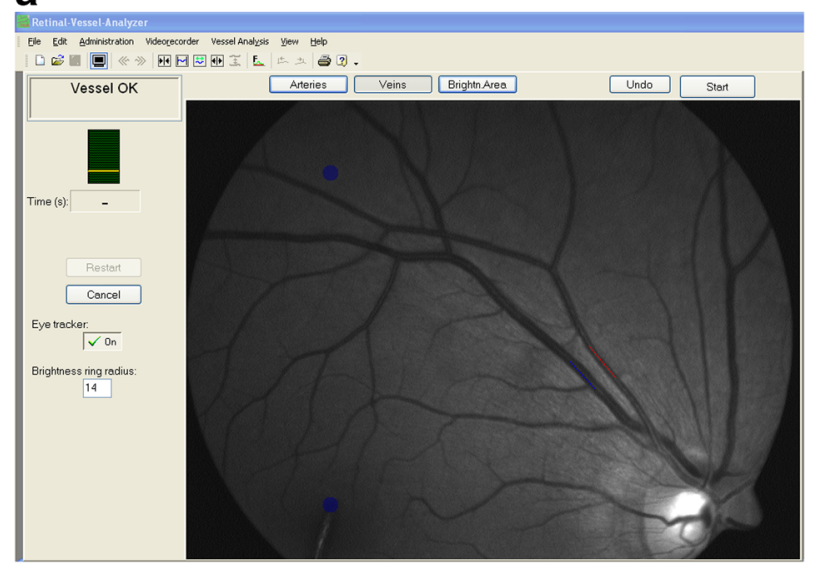

b

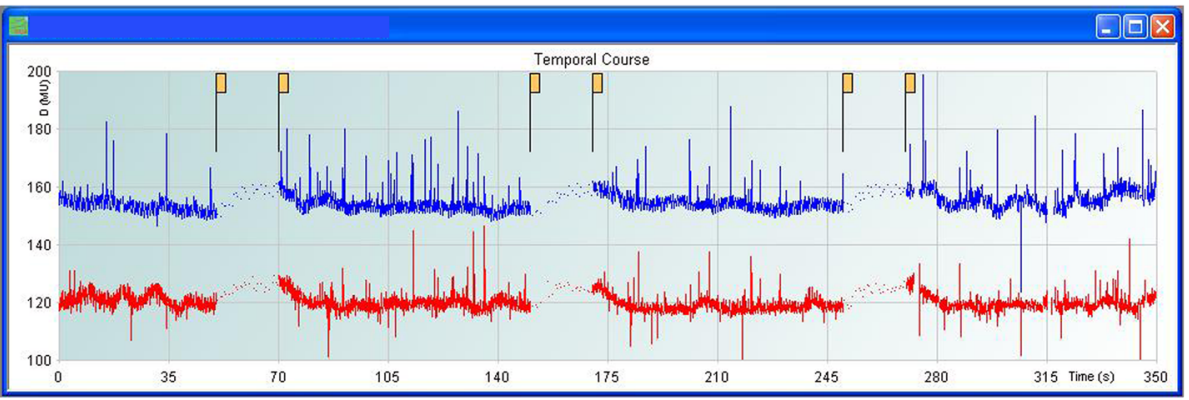

C
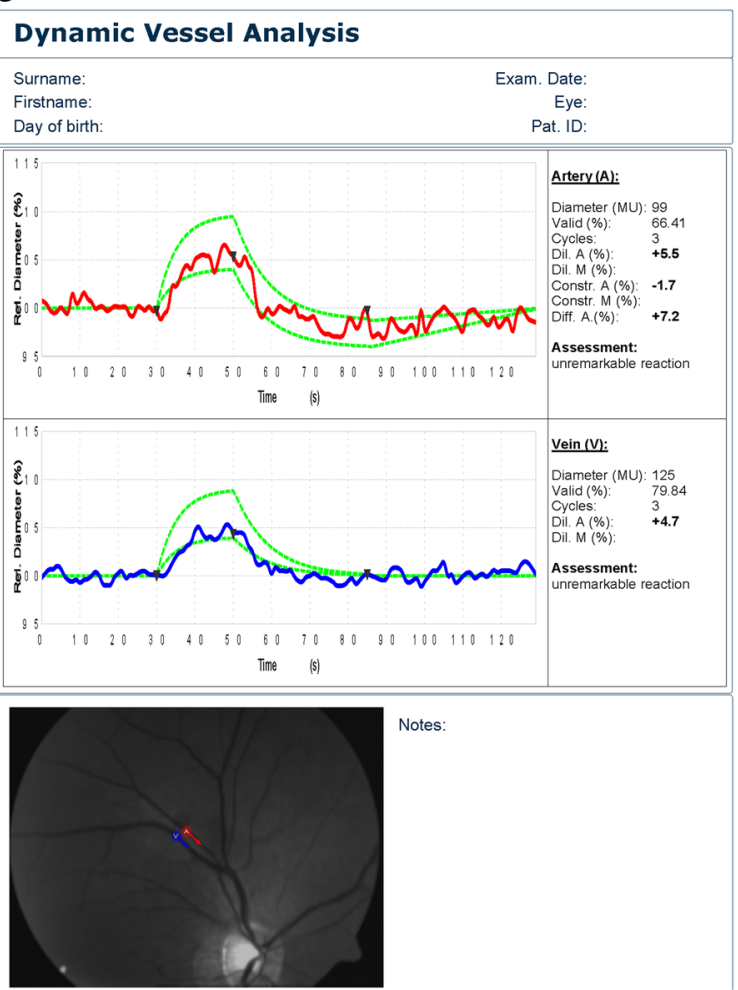

Oxygen saturation The retina is one of the most metabolically active tissues in the human body and as such consumes oxygen more rapidly than other tissues [88]. Retinal oxygen d
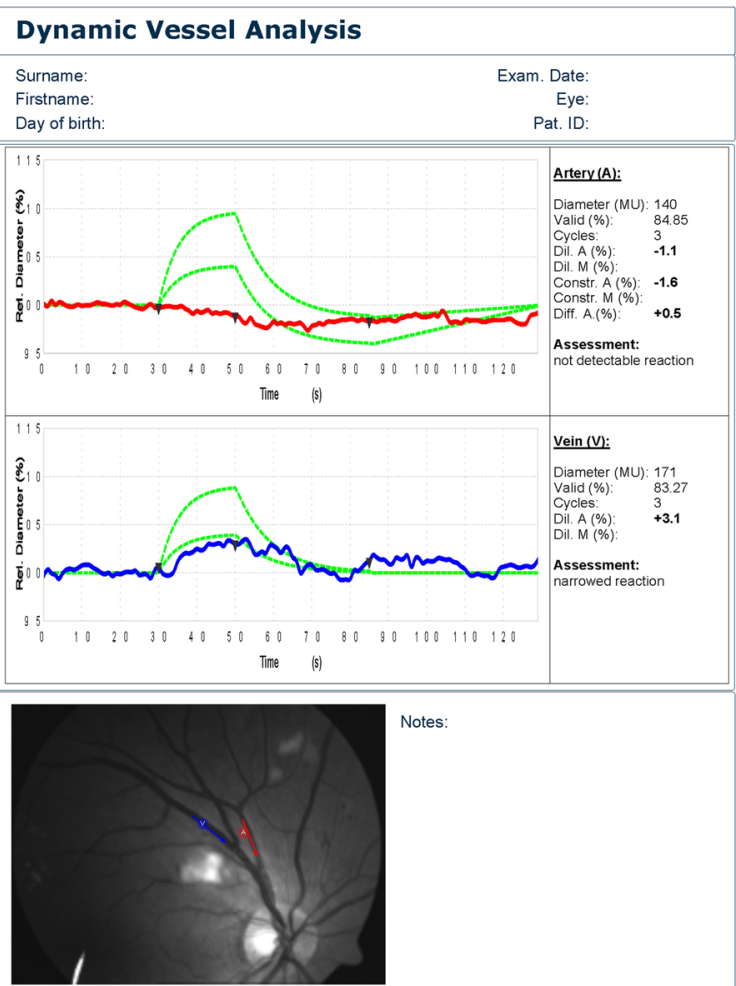

saturation may provide valuable information on retinal metabolism, and it can now be estimated using a technique known as retinal oximetry. Retinal oximetry is based on measurements 
of the colour of haemoglobin in the retina from the reflection of light at two different wavelengths $(586 \mathrm{~nm}$ light and $605 \mathrm{~nm}$ light) (Fig. 5) [89, 90]. Oxygen saturation is defined as the proportion (percentage) of haemoglobin that is bound to oxygen. Recent studies have observed increased retinal oxygen saturation and a lower arteriovenous oxygen saturation

\section{a}

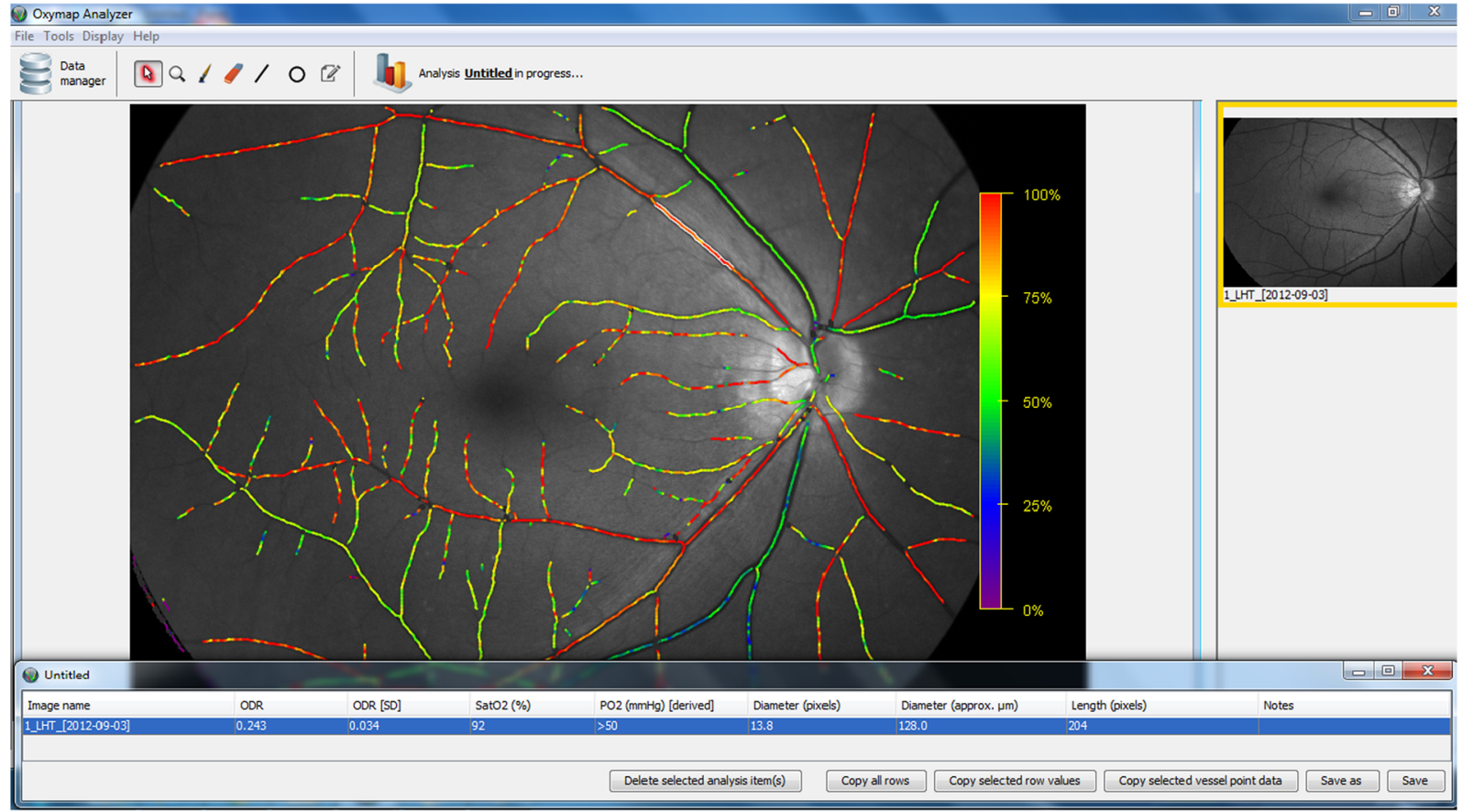

b

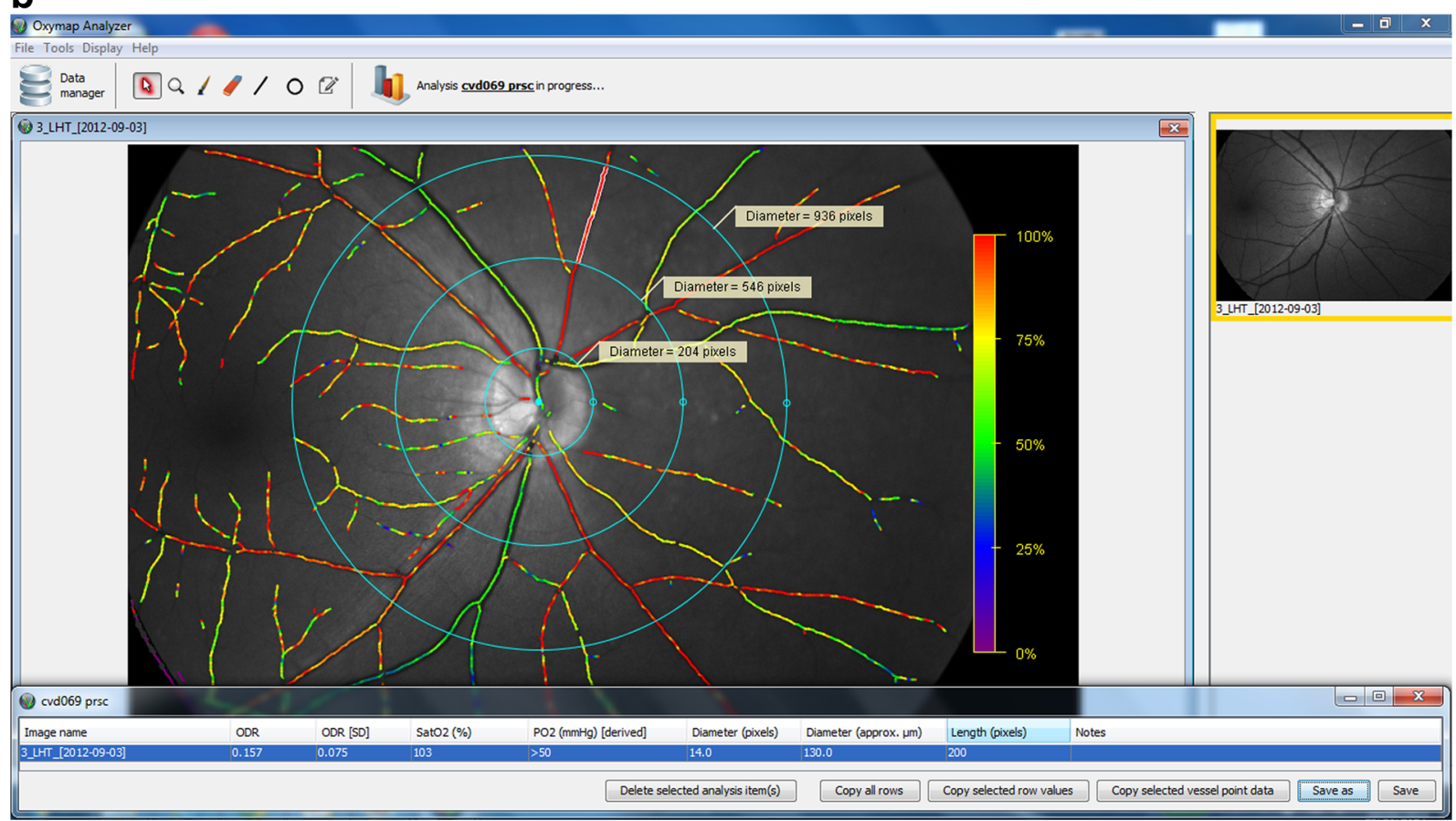

Fig. 5 Pseudocolour maps of retinal vessel oxygen saturation in (a) macular-centred and (b) optic disc-centred view using the Oxymap T1 retinal oximeter (Oxymap, Reykjavik, Iceland) in a diabetic patient. The colour indicates the calculated oxygen saturation of retinal vessels as a percentage. Seven variables can automatically be calculated for selected vessel segment from the built-in specialised software: mean optical density ratio, standard deviation of optical density ratio, calculated oxygen saturation $\left[\mathrm{SatO}_{2}(\%)\right]$, calculated partial pressure of oxygen $\left[\mathrm{PO}_{2}\right.$ $(\mathrm{mmHg})]$, mean diameter of the selected vessel segments in pixels, approximate mean diameter of the selected vessels in micrometres, and length of the selected vessel segment in pixels 
difference as measured by retinal oximeter in diabetic people with diabetic retinopathy [91, 92] compared with normal controls [93, 94]. It has been speculated that increased oxygen saturation in retinal arterioles may be the result of either increased retinal blood flow or reduced oxygen extraction in the eye resulting in a higher oxygen saturation in the retinal venules and a reduced arteriovenous oxygen gradient to drive the countercurrent exchange [93]. Oxygen distribution may be affected by at least three mechanisms: shunting and capillary nonperfusion, thickening of capillary basement membranes, and greater oxygen affinity of haemoglobin in diabetic patients $[92,94]$. In addition, retinal oxygen tone is tightly controlled by autoregulation of the vessel diameters [95]. These data, together with impaired flicker light-induced vasodilation in diabetes, lend support to the hypothesis of an impaired regulation of oxygen supply to the diabetic retina [96].

\section{Technological challenges in retinal vascular imaging}

There are various technological challenges in retinal vascular imaging that limit the reliability of measurements. Cataract and other ocular media opacities (e.g. vitreous haemorrhage), pupil size and retinal pigmentation may result in variations of image brightness, focus and contrast of retinal vascular images, which affect the precision of measurements of retinal vascular structure and function. Refractive error (e.g. myopia) and axial length may also affect the magnification and apparent dimensions of retinal structures on fundus photography. Ambient haemodynamic changes during the cardiac cycle may potentially affect the variability of the measurements. Photographic technique, camera type (e.g. mydriatic, nonmydriatic, hand-held) and grader variability may also affect the image quality. These factors should be accounted for when possible. Full automation of measurements is an important goal and further development of retinal vascular imaging technology should aim to minimise artefacts.

\section{Retinal vasculature measurements in clinical practice}

Retinal vascular imaging offers an opportunity to examine the effects of diabetes on the microcirculation, and may be an additional test in clinical practice. However, to date, the strength of associations between retinal vascular changes and disease prediction has been relatively modest. Moreover, consistency of associations has not been demonstrated, and improvements in predicted risk in diabetic cohorts independent of traditional risk factors are small. Nevertheless, there is great potential for retinal vascular imaging, particularly in the following two clinical scenarios.
Retinal vascular imaging as a risk stratification tool for retinal and systemic diabetic complications Estimation of a diabetic patient's risk of retinal and systemic vascular complication development is crucial as early treatment is associated with better outcomes [97]. While classical CVD risk factors (e.g. elevated serum cholesterol level and blood pressure) are used clinically to assess a person's risk of CVD, these risk factors do not fully explain the higher risk of CVD events in diabetics [91, 92].

Retinal vascular calibre may be predictive of the risk of diabetic retinopathy and CVD $[67,98]$. In the WESDR study, retinal venular widening over time was associated with the subsequent incidence and progression of diabetic retinopathy [99]. Changes in retinal vascular calibre may also represent an individualised indicator of how well diabetes is controlled [100]. Recent studies in the general population have demonstrated that the addition of retinal vascular imaging to existing models of stroke can improve risk stratification [101, 102]. However, the overall improvement is only about $10 \%$ beyond that of established risk factors. Further studies are needed to determine whether detection of retinal vascular changes has additional value beyond the methods currently used to stratify the risk of diabetic retinopathy or systemic vascular complications, and to target the test to a more specific subgroup of patients who could benefit from more intensive investigations. This includes work to optimise the risk-prediction algorithm, to determine how it may influence clinical decision-making, and to estimate the cost-effectiveness and acceptability of this type of investigation to patients in different settings.

Retinal vascular imaging as a tool to monitor treatment outcomes Changes in retinal vasculature may also be markers of the effectiveness of new therapies and reflect treatment response. For example, studies have demonstrated changes in retinal vascular calibre in response to treatment in patients with DMO. DMO results from endothelial cell dysfunction, retinal capillary basement membrane thickening and a reduction in the number of pericytes, leading to increased permeability and incompetence of retinal vasculature. Lundberg et al have reported that following focal/grid laser treatment of DMO, the macular arteriole and venule diameters decreased [103], and Wickremasinghe et al reported a significant narrowing effect on both retinal arteriolar and venular calibres in patients with DMO in response to intravitreal triamcinolone [104]. Studies have also demonstrated regression of retinal vascular changes in response to blood pressure reduction and that regression differs between different antihypertensive regimens [105-107].

VEGF increases vascular permeability and instigates vessel leakage leading to DMO, and higher levels of VEGF have been found in the aqueous humour of patients with DMO $[58,108]$. Treatment of DMO has improved dramatically during the last few years. Injections of anti-VEGF drugs (e.g. 
ranibizumab, bevacizumab and aflibercept), sometimes in combination with laser photocoagulation, are currently the mainstay of treatment [109]. However, there remains a lack of vascular biomarkers to indicate retinal microvasculature changes in response to DMO treatment. Retinal venular widening has been associated with a poorer response to intravitreal ranibizumab injections in patients with neovascular agerelated macular degeneration [110]. The evidence to date suggests that quantitative measurement of retinal vessels may allow physicians to monitor the progress and success of both local and systemic treatment.

\section{Future research}

There are several areas for future research. First, while data from the above epidemiological and clinical studies suggest that retinal vascular changes are markers of early retinal as well as systemic microvascular damage, the specific underlying pathophysiological mechanisms (e.g. impaired vascular tone, autoregulation, inflammation, endothelial dysfunction) are still unclear. Experimental research and animal models may shed further light onto these.

Second, studies to date have primarily focused on retinal photography, a snapshot measurement of retinal vascular changes at baseline, and the associations of these changes with different clinical outcomes [100]. Dynamic functional changes in retinal vessels can now be detected and monitored over time by the use of other retinal imaging technologies. Additional studies are required to further elucidate the clinical relevance of assessing longitudinal changes in retinal vasculature.

Third, the current range of software programs for measuring retinal vascular changes is not fully automated nor easy to use without standardised protocols, training and additional input by technicians. New software programs incorporating automated measurement and documentation of retinal vascular changes and risk prediction algorithms are being developed to improve precision and reliability. The next generation of software should reduce existing limitations and improve its implementation in a wider clinical setting.

There are many new retinal vascular imaging technologies. For example, adaptive optics retinal imaging [111, 112], en face optical coherence tomography angiography [113], Doppler optical coherence tomography [114], scanning laser Doppler flowmetry [115], spectral-domain optical coherence tomography [116], and sequential and diameter response analysis [117], are now being studied to further measure and analyse the detailed structure and functions of the retina (including the foveal capillary network, choroidal vasculature, blood flow, choroidal flow, wall:lumen ratio and retinal vessel responses to flickering light). These developments may offer an improved understanding of how early diabetic complications develop and offer improved risk stratification in clinical practice.

\section{Conclusion}

The retina is traditionally seen as a site of diabetic damage that results in the classical signs of diabetic retinopathy and subsequent vision loss. The retinal blood vessels, however, provide additional information that allow the study of early structural and functional changes in the microvasculature, possibly prior to the onset of clinically significant microvascular and macrovascular complications of diabetes. Studies using new imaging techniques have provided data and strong evidence that quantitatively measured retinal vascular changes from retinal photographs mirror preclinical changes in the microcirculation associated with diabetes and predict a range of clinical complications. These retinal vascular measures are therefore potential biomarkers of early microvascular damage in pre-diabetes, diabetes and diabetic complications, and may be tools for monitoring interventions. Further development of retinal vascular imaging techniques, with more consistent data on incremental benefit and clinical utility, will allow the translation of retinal vascular imaging as a useful tool to improve the diagnosis, prognostication and management of diabetes in clinical practice.

Funding TYW is supported by a National Medical Research Council STaR Investigator Award.

Duality of interest The authors declare that there is no duality of interest associated with this manuscript.

Contribution statement All authors were responsible for drafting the article and revising it critically for important intellectual content. All authors approved this version to be published.

\section{References}

1. International Diabetes Federation (2014) IDF diabetes atlas, 6th edn. IDF, Brussels

2. Terry T, Raravikar K, Chokrungvaranon N, Reaven PD (2012) Does aggressive glycemic control benefit macrovascular and microvascular disease in type 2 diabetes? Insights from ACCORD, ADVANCE, and VADT. Curr Cardiol Rep 14:79-88

3. Sarwar N, Gao P, Seshasai SR et al (2010) Diabetes mellitus, fasting blood glucose concentration, and risk of vascular disease: a collaborative meta-analysis of 102 prospective studies. Lancet 375:22152222

4. Nathan DM (1993) Long-term complications of diabetes mellitus. N Engl J Med 328:1676-1685

5. Chew EY, Ambrosius WT, Davis MD et al (2010) Effects of medical therapies on retinopathy progression in type 2 diabetes. $\mathrm{N}$ Engl $\mathrm{J}$ Med 363:233-244 
6. Giorgino F, Leonardini A, Laviola L (2013) Cardiovascular disease and glycemic control in type 2 diabetes: now that the dust is settling from large clinical trials. Ann NY Acad Sci 1281:36-50

7. Brown A, Reynolds LR, Bruemmer D (2010) Intensive glycemic control and cardiovascular disease: an update. Nat Rev Cardiol 7: 369-375

8. Cheung N, Mitchell P, Wong TY (2010) Diabetic retinopathy. Lancet 376:124-136

9. Cheung CY, Ikram MK, Sabanayagam C, Wong TY (2012) Retinal microvasculature as a model to study the manifestations of hypertension. Hypertension 60:1094-1103

10. Haritoglou C, Kernt M, Neubauer A et al (2014) Microaneurysm formation rate as a predictive marker for progression to clinically significant macular edema in nonproliferative diabetic retinopathy. Retina 34:157-164

11. Ribeiro ML, Nunes SG, Cunha-Vaz JG (2013) Microaneurysm turnover at the macula predicts risk of development of clinically significant macular edema in persons with mild nonproliferative diabetic retinopathy. Diabetes Care 36:1254-1259

12. Orasanu G, Plutzky J (2009) The pathologic continuum of diabetic vascular disease. J Am Coll Cardiol 53:S35-S42

13. Wiernsperger NF (2001) In defense of microvascular constriction in diabetes. Clin Hemorheol Microcirc 25:55-62

14. Sheetz MJ, King GL (2002) Molecular understanding of hyperglycemia's adverse effects for diabetic complications. JAMA 288: 2579-2588

15. Anonymous (1993) The effect of intensive treatment of diabetes on the development and progression of long-term complications in insulin-dependent diabetes mellitus. The Diabetes Control and Complications Trial Research Group. N Eng1 J Med 329:977-986

16. Brownlee M (2005) The pathobiology of diabetic complications: a unifying mechanism. Diabetes 54:1615-1625

17. Ejaz S, Chekarova I, Ejaz A, Sohail A, Lim CW (2008) Importance of pericytes and mechanisms of pericyte loss during diabetes retinopathy. Diabetes Obes Metab 10:53-63

18. Yu JY, Lyons TJ (2013) Modified lipoproteins in diabetic retinopathy: a local action in the retina. J Clin Exp Ophthalmol 4:314

19. Wolf G, Chen S, Ziyadeh FN (2005) From the periphery of the glomerular capillary wall toward the center of disease: podocyte injury comes of age in diabetic nephropathy. Diabetes 54:16261634

20. Murata T, Nagai R, Ishibashi T, Inomuta H, Ikeda K, Horiuchi S (1997) The relationship between accumulation of advanced glycation end products and expression of vascular endothelial growth factor in human diabetic retinas. Diabetologia 40:764-769

21. Klein R, Klein BE, Moss SE et al (2003) Retinal vascular abnormalities in persons with type 1 diabetes: the Wisconsin Epidemiologic Study of Diabetic Retinopathy: XVIII. Ophthalmology 110:2118-2125

22. Klein R, Klein BE, Moss SE et al (2004) The relation of retinal vessel caliber to the incidence and progression of diabetic retinopathy: XIX: the Wisconsin Epidemiologic Study of Diabetic Retinopathy. Arch Ophthalmol 122:76-83

23. Hubbard LD, Brothers RJ, King WN et al (1999) Methods for evaluation of retinal microvascular abnormalities associated with hypertension/sclerosis in the Atherosclerosis Risk in Communities Study. Ophthalmology 106:2269-2280

24. Wong TY, Knudtson MD, Klein R, Klein BE, Meuer SM, Hubbard LD (2004) Computer-assisted measurement of retinal vessel diameters in the Beaver Dam Eye Study: methodology, correlation between eyes, and effect of refractive errors. Ophthalmology 111: $1183-1190$

25. Murray CD (1926) The physiological principle of minimum work: I. The vascular system and the cost of blood volume. Proc Natl Acad Sci U S A 12:207-214
26. Tooke JE (1995) Microvascular function in human diabetes. A physiological perspective. Diabetes 44:721-726

27. Hughes AD, Wong TY, Witt $N$ et al (2009) Determinants of retinal microvascular architecture in normal subjects. Microcirculation 16: 159-166

28. Thomas GN, Ong SY, Tham YC et al (2014) Measurement of macular fractal dimension using a computer-assisted program. Invest Ophthalmol Vis Sci 55:2237-2243

29. Patton N, Pattie A, Macgillivray T et al (2007) The association between retinal vascular network geometry and cognitive ability in an elderly population. Invest Ophthalmol Vis Sci 48:1995-2000

30. Doubal FN, MacGillivray TJ, Patton N, Dhillon B, Dennis MS, Wardlaw JM (2010) Fractal analysis of retinal vessels suggests that a distinct vasculopathy causes lacunar stroke. Neurology 74:11021107

31. Cheung CY, Tay WT, Mitchell P et al (2011) Quantitative and qualitative retinal microvascular characteristics and blood pressure. J Hypertens 29:1380-1391

32. Cheung CY, Hsu W, Lee ML et al (2010) A new method to measure peripheral retinal vascular caliber over an extended area. Microcirculation 17:495-503

33. Kohner EM, Stratton IM, Aldington SJ, Turner RC, Matthews DR (1999) Microaneurysms in the development of diabetic retinopathy (UKPDS 42). UK Prospective Diabetes Study Group. Diabetologia 42:1107-1112

34. Hellstedt T, Immonen I (1996) Disappearance and formation rates of microaneurysms in early diabetic retinopathy. $\mathrm{Br} \mathrm{J}$ Ophthalmol 80:135-139

35. Nunes S, Pires I, Rosa A, Duarte L, Bernardes R, Cunha-Vaz J (2009) Microaneurysm turnover is a biomarker for diabetic retinopathy progression to clinically significant macular edema: findings for type 2 diabetics with nonproliferative retinopathy. Ophthalmologica 223:292-297

36. Leicht SF, Kernt M, Neubauer A et al (2014) Microaneurysm turnover in diabetic retinopathy assessed by automated RetmarkerDR image analysis - potential role as biomarker of response to ranibizumab treatment. Ophthalmologica 231:198-203

37. Wong TY, Klein R, Sharrett AR et al (2002) Retinal arteriolar narrowing and risk of diabetes mellitus in middle-aged persons. JAMA 287:2528-2533

38. Wong TY, Shankar A, Klein R, Klein BE, Hubbard LD (2005) Retinal arteriolar narrowing, hypertension, and subsequent risk of diabetes mellitus. Arch Intern Med 165:1060-1065

39. Ikram MK, Janssen JA, Roos AM et al (2006) Retinal vessel diameters and risk of impaired fasting glucose or diabetes: the Rotterdam study. Diabetes 55:506-510

40. Kifley A, Wang JJ, Cugati S, Wong TY, Mitchell P (2007) Retinal vascular caliber, diabetes, and retinopathy. Am J Ophthalmol 143: 1024-1026

41. Tikellis G, Wang JJ, Tapp R et al (2007) The relationship of retinal vascular calibre to diabetes and retinopathy: the Australian Diabetes, Obesity and Lifestyle (AusDiab) study. Diabetologia 50: 2263-2271

42. Nguyen TT, Wang JJ, Islam FM et al (2008) Retinal arteriolar narrowing predicts incidence of diabetes: the Australian Diabetes, Obesity and Lifestyle (AusDiab) Study. Diabetes 57:536-539

43. Nguyen TT, Wang JJ, Sharrett AR et al (2008) Relationship of retinal vascular caliber with diabetes and retinopathy: the MultiEthnic Study of Atherosclerosis (MESA). Diabetes Care 31:544 549

44. Islam FM, Nguyen TT, Wang JJ et al (2009) Quantitative retinal vascular calibre changes in diabetes and retinopathy: the Singapore Malay Eye Study. Eye (Lond) 23:1719-1724

45. Tsai AS, Wong TY, Lavanya R et al (2011) Differential association of retinal arteriolar and venular caliber with diabetes and retinopathy. Diabetes Res Clin Pract 94:291-298 
46. Cheung CY, Lamoureux E, Ikram MK et al (2012) Retinal vascular geometry in Asian persons with diabetes and retinopathy. J Diabetes Sci Technol 6:595-605

47. Sasongko MB, Wong TY, Nguyen TT, Cheung CY, Shaw JE, Wang JJ (2011) Retinal vascular tortuosity in persons with diabetes and diabetic retinopathy. Diabetologia 54:2409-2416

48. Sasongko MB, Wang JJ, Donaghue KC et al (2010) Alterations in retinal microvascular geometry in young type 1 diabetes. Diabetes Care 33:1331-1336

49. Sun C, Wang JJ, Mackey DA, Wong TY (2009) Retinal vascular caliber: systemic, environmental, and genetic associations. Surv Ophthalmol 54:74-95

50. Roy MS, Klein R, Janal MN (2012) Relationship of retinal vessel caliber to cardiovascular disease and mortality in African Americans with type 1 diabetes mellitus. Arch Ophthalmol 130: 561-567

51. Cheung N, Rogers SL, Donaghue KC, Jenkins AJ, Tikellis G, Wong TY (2008) Retinal arteriolar dilation predicts retinopathy in adolescents with type 1 diabetes. Diabetes Care 31:1842-1846

52. Broe R, Rasmussen ML, Frydkjaer-Olsen U et al (2014) Retinal vessel calibers predict long-term microvascular complications in type 1 diabetes: the Danish Cohort of Pediatric Diabetes 1987 (DCPD1987). Diabetes 63:3906-3914

53. Broe R, Rasmussen ML, Frydkjaer-Olsen U et al (2014) Retinal vascular fractals predict long-term microvascular complications in type 1 diabetes mellitus: the Danish Cohort of Pediatric Diabetes 1987 (DCPD1987). Diabetologia 57:2215-2221

54. Klein R, Klein BE, Moss SE, Wong TY (2007) Retinal vessel caliber and microvascular and macrovascular disease in type 2 diabetes: XXI: the Wisconsin Epidemiologic Study of Diabetic Retinopathy. Ophthalmology 114:1884-1892

55. Rogers SL, Tikellis G, Cheung N et al (2008) Retinal arteriolar caliber predicts incident retinopathy: the Australian Diabetes, Obesity and Lifestyle (AusDiab) study. Diabetes Care 31:761-763

56. Ikram MK, Cheung CY, Lorenzi M, Klein R, Jones TL, Wong TY (2013) Retinal vascular caliber as a biomarker for diabetes microvascular complications. Diabetes Care 36:750-759

57. Falck A, Laatikainen L (1995) Retinal vasodilation and hyperglycaemia in diabetic children and adolescents. Acta Ophthalmol Scand 73:119-124

58. Antonetti DA, Klein R, Gardner TW (2012) Diabetic retinopathy. N Engl J Med 366:1227-1239

59. Simo R, Hernandez C (2012) Neurodegeneration is an early event in diabetic retinopathy: therapeutic implications. Br J Ophthalmol 96: $1285-1290$

60. Klein R, Knudtson MD, Klein BE et al (2010) The relationship of retinal vessel diameter to changes in diabetic nephropathy structural variables in patients with type 1 diabetes. Diabetologia 53:1638 1646

61. Wong TY, Shankar A, Klein R, Klein BE (2004) Retinal vessel diameters and the incidence of gross proteinuria and renal insufficiency in people with type 1 diabetes. Diabetes 53:179-184

62. Sabanayagam C, Tai ES, Lee J, Lim SC, Wong TY (2010) Retinal vessel caliber and peripheral neuropathy in diabetic participants. Microcirculation 17:297-302

63. Ding J, Cheung CY, Ikram MK et al (2012) Early retinal arteriolar changes and peripheral neuropathy in diabetes. Diabetes Care 35: 1098-1104

64. Grauslund J, Hodgson L, Kawasaki R, Green A, Sjolie AK, Wong TY (2009) Retinal vessel calibre and micro- and macrovascular complications in type 1 diabetes. Diabetologia 52:2213-2217

65. van Hecke MV, Dekker JM, Stehouwer CD et al (2005) Diabetic retinopathy is associated with mortality and cardiovascular disease incidence: the EURODIAB prospective complications study. Diabetes Care 28:1383-1389
66. Cheung N, Wang JJ, Klein R, Couper DJ, Sharrett AR, Wong TY (2007) Diabetic retinopathy and the risk of coronary heart disease: the Atherosclerosis Risk in Communities Study. Diabetes Care 30: 1742-1746

67. Cheung N, Wong TY (2008) Diabetic retinopathy and systemic vascular complications. Prog Retin Eye Res 27:161-176

68. Klein BE, Klein R, McBride PE et al (2004) Cardiovascular disease, mortality, and retinal microvascular characteristics in type 1 diabetes: Wisconsin Epidemiologic Study of Diabetic Retinopathy. Arch Intern Med 164:1917-1924

69. Miller RG, Prince CT, Klein R, Orchard TJ (2009) Retinal vessel diameter and the incidence of coronary artery disease in type 1 diabetes. Am J Ophthalmol 147:653-660

70. Grauslund J, Green A, Kawasaki R, Hodgson L, Sjolie AK, Wong TY (2010) Retinal vascular fractals and microvascular and macrovascular complications in type 1 diabetes. Ophthalmology 117:1400-1405

71. Lim M, Sasongko MB, Ikram MK et al (2013) Systemic associations of dynamic retinal vessel analysis: a review of current literature. Microcirculation 20:257-268

72. Nguyen TT, Kawasaki R, Wang JJ et al (2009) Flicker light-induced retinal vasodilation in diabetes and diabetic retinopathy. Diabetes Care 32:2075-2080

73. Mandecka A, Dawczynski J, Blum M et al (2007) Influence of flickering light on the retinal vessels in diabetic patients. Diabetes Care 30:3048-3052

74. Garhofer G, Zawinka C, Resch H, Kothy P, Schmetterer L, Dorner GT (2004) Reduced response of retinal vessel diameters to flicker stimulation in patients with diabetes. Br J Ophthalmol 88:887-891

75. Lecleire-Collet A, Audo I, Aout M et al (2011) Evaluation of retinal function and flicker light-induced retinal vascular response in normotensive patients with diabetes without retinopathy. Invest Ophthalmol Vis Sci 52:2861-2867

76. Lott ME, Slocomb JE, Shivkumar V et al (2013) Impaired retinal vasodilator responses in prediabetes and type 2 diabetes. Acta Ophthalmol 91:e462-e469

77. Patel SR, Bellary S, Qin L, Balanos GM, McIntyre D, Gherghel D (2012) Abnormal retinal vascular reactivity in individuals with impaired glucose tolerance: a preliminary study. Invest Ophthalmol Vis Sci 53:5102-5108

78. Sasongko MB, Wong TY, Nguyen TT et al (2012) Serum apolipoproteins are associated with systemic and retinal microvascular function in people with diabetes. Diabetes 61:1785-1792

79. Nguyen TT, Kawasaki R, Kreis AJ et al (2009) Correlation of lightflicker-induced retinal vasodilation and retinal vascular caliber measurements in diabetes. Invest Ophthalmol Vis Sci 50:5609-5613

80. Al-Fiadh AH, Farouque O, Kawasaki R et al (2014) Retinal microvascular structure and function in patients with risk factors of atherosclerosis and coronary artery disease. Atherosclerosis 233:478484

81. Riva CE, Geiser M, Petrig BL (2010) Ocular blood flow assessment using continuous laser Doppler flowmetry. Acta Ophthalmol 88: 622-629

82. Pournaras CJ, Riva CE (2013) Retinal blood flow evaluation. Ophthalmologica 229:61-74

83. Clermont AC, Bursell SE (2007) Retinal blood flow in diabetes. Microcirculation 14:49-61

84. Nagaoka T, Sato E, Takahashi A, Yokota H, Sogawa K, Yoshida A (2010) Impaired retinal circulation in patients with type 2 diabetes mellitus: retinal laser Doppler velocimetry study. Invest Ophthalmol Vis Sci 51:6729-6734

85. Bursell SE, Clermont AC, Kinsley BT, Simonson DC, Aiello LM, Wolpert HA (1996) Retinal blood flow changes in patients with insulin-dependent diabetes mellitus and no diabetic retinopathy. Invest Ophthalmol Vis Sci 37:886-897 
86. Patel V, Rassam S, Newsom R, Wiek J, Kohner E (1992) Retinal blood flow in diabetic retinopathy. BMJ 305:678-683

87. Konno S, Feke GT, Yoshida A, Fujio N, Goger DG, Buzney SM (1996) Retinal blood flow changes in type I diabetes. A long-term follow-up study. Invest Ophthalmol Vis Sci 37:1140-1148

88. Kur J, Newman EA, Chan-Ling T (2012) Cellular and physiological mechanisms underlying blood flow regulation in the retina and choroid in health and disease. Prog Retin Eye Res 31:377-406

89. Hardarson SH (2013) Retinal oximetry. Acta Ophthalmol 91(Thesis 2):1-47

90. Yip W, Siantar R, Perera SA et al (2014) Reliability and determinants of retinal vessel oximetry measurements in healthy eyes. Invest Ophthalmol Vis Sci 55:7104-7110

91. Hammer M, Vilser W, Riemer T et al (2009) Diabetic patients with retinopathy show increased retinal venous oxygen saturation. Graefes Arch Clin Exp Ophthalmol 247:1025-1030

92. Hardarson SH, Stefansson E (2012) Retinal oxygen saturation is altered in diabetic retinopathy. Br J Ophthalmol 96:560-563

93. Jorgensen CM, Hardarson SH, Bek T (2014) The oxygen saturation in retinal vessels from diabetic patients depends on the severity and type of vision-threatening retinopathy. Acta Ophthalmol 92:34-39

94. Khoobehi B, Firn K, Thompson H, Reinoso M, Beach J (2013) Retinal arterial and venous oxygen saturation is altered in diabetic patients. Invest Ophthalmol Vis Sci 54:7103-7106

95. Pournaras CJ, Rungger-Brandle E, Riva CE, Hardarson SH, Stefansson E (2008) Regulation of retinal blood flow in health and disease. Prog Retin Eye Res 27:284-330

96. Hammer M, Heller T, Jentsch S et al (2012) Retinal vessel oxygen saturation under flicker light stimulation in patients with nonproliferative diabetic retinopathy. Invest Ophthalmol Vis Sci 53:4063-4068

97. Pratley RE (2013) The early treatment of type 2 diabetes. Am J Med 126:S2-S9

98. Wong TY (2011) Retinal vessel diameter as a clinical predictor of diabetic retinopathy progression: time to take out the measuring tape. Arch Ophthalmol 129:95-96

99. Klein R, Myers CE, Lee KE, Gangnon R, Klein BE (2012) Changes in retinal vessel diameter and incidence and progression of diabetic retinopathy. Arch Ophthalmol 130:749-755

100. Cheung N, Wong TY (2012) Predicting risk of diabetic retinopathy from retinal vessel analysis: personalized medicine in transition. Arch Ophthalmol 130:783-784

101. McGeechan K, Liew G, Macaskill P et al (2009) Prediction of incident stroke events based on retinal vessel caliber: a systematic review and individual-participant meta-analysis. Am J Epidemiol 170:1323-1332

102. Cheung CY, Tay WT, Ikram MK et al (2013) Retinal microvascular changes and risk of stroke: the Singapore Malay Eye Study. Stroke 44:2402-2408

103. Lundberg K, Kawasaki R, Sjolie AK, Wong TY, Grauslund J (2013) Localized changes in retinal vessel caliber after focal/grid laser treatment in patients with diabetic macular edema: a measure of treatment response? Retina 33:2089-2095
104. Wickremasinghe SS, Rogers SL, Gillies MC, Zhu M, Wong TY (2008) Retinal vascular caliber changes after intravitreal triamcinolone treatment for diabetic macular edema. Invest Ophthalmol Vis Sci 49:4707-4711

105. Hughes AD, Stanton AV, Jabbar AS, Chapman N, Martinez-Perez ME, McG Thom SA (2008) Effect of antihypertensive treatment on retinal microvascular changes in hypertension. J Hypertens 26: 1703-1707

106. Dahlof B, Stenkula S, Hansson L (1992) Hypertensive retinal vascular changes: relationship to left ventricular hypertrophy and arteriolar changes before and after treatment. Blood Press 1:35-44

107. Thom S, Stettler C, Stanton A et al (2009) Differential effects of antihypertensive treatment on the retinal microcirculation: an AngloScandinavian cardiac outcomes trial substudy. Hypertension 54: 405-408

108. Aiello LP, Edwards AR, Beck RW et al (2010) Factors associated with improvement and worsening of visual acuity 2 years after focal/grid photocoagulation for diabetic macular edema. Ophthalmology 117:946-953

109. Regnier S, Malcolm W, Allen F, Wright J, Bezlyak V (2014) Efficacy of anti-VEGF and laser photocoagulation in the treatment of visual impairment due to diabetic macular edema: a systematic review and network meta-analysis. PLoS One 9:e102309

110. Wickremasinghe SS, Busija L, Guymer RH, Wong TY, Qureshi S (2012) Retinal venular caliber predicts visual outcome after intravitreal ranibizumab injection treatments for neovascular AMD. Invest Ophthalmol Vis Sci 53:37-41

111. Lombardo M, Serrao S, Devaney N, Parravano M, Lombardo G (2013) Adaptive optics technology for high-resolution retinal imaging. Sensors (Basel) 13:334-366

112. Koch E, Rosenbaum D, Brolly A et al (2014) Morphometric analysis of small arteries in the human retina using adaptive optics imaging: relationship with blood pressure and focal vascular changes. J Hypertens 32:890-898

113. Jia Y, Bailey ST, Wilson DJ et al (2014) Quantitative optical coherence tomography angiography of choroidal neovascularization in age-related macular degeneration. Ophthalmology 121:1435-1444

114. Leitgeb RA, Werkmeister RM, Blatter C, Schmetterer L (2014) Doppler optical coherence tomography. Prog Retin Eye Res 41: 26-43

115. Harazny JM, Raff U, Welzenbach J et al (2011) New software analyses increase the reliability of measurements of retinal arterioles morphology by scanning laser Doppler flowmetry in humans. J Hypertens 29:777-782

116. Muraoka Y, Tsujikawa A, Kumagai K et al (2013) Age- and hypertension-dependent changes in retinal vessel diameter and wall thickness: an optical coherence tomography study. Am J Ophthalmol 156:706-714

117. Heitmar R, Blann AD, Cubbidge RP, Lip GY, Gherghel D (2010) Continuous retinal vessel diameter measurements: the future in retinal vessel assessment? Invest Ophthalmol Vis Sci 51:5833-5839 